\title{
Da Compra de Produtos e Serviços Culturais ao Direito de Produzir Cultura: Análise de um Paradigma Emergente*
}

\author{
Luciana Lima ${ }^{1}$ \\ Pablo Ortellado ${ }^{2}$
}

${ }^{1}$ Mestranda no Programa de Pós-Graduação em Estudos Culturais da Escola de Artes, Ciências e Humanidades da Universidade de São Paulo (USP). E-mail: lupblima@usp.br ${ }^{2}$ Professor do curso de Gestão de Políticas Públicas e do Programa de Pós-Graduação em Estudos Culturais da Escola de Artes, Ciências e Humanidades da Universidade de São Paulo (USP). E-mail: paort@usp.br

$\mathrm{O}$ financiamento das atividades culturais tem dois paradigmas clássicos: o financiamento público e o mercantil. O primeiro consiste na ação direta do estado ou no financiamento com recursos estatais de práticas culturais da sociedade civil; o segundo ancora-se na tradição liberal ou neoliberal, cuja mais recente expressão são as correntes dominantes da economia criativa. A partir de uma revisão teórica e da análise de duas políticas brasileiras - o programa Cultura Viva e a Lei de Fomento ao Teatro da cidade de São Paulo - argumentamos que essas experiências constituem a gênese de um terceiro paradigma que identificamos e desenvolvemos. Esse paradigma não busca financiar produtos culturais, mas o processo de produção cultural e se orienta assim para a constituição de um direito social: o direito de produzir cultura.

Inicialmente discutimos de maneira esquemática os argumentos e críticas historicamente utilizados no debate pelo estabelecimento de políticas de financiamento público da cultura, sobretudo na modalidade editais públicos. Em seguida apresentamos os argumentos e críticas relativos ao financiamento mercantil da cultura. Mostramos que, embo-

\footnotetext{
* Agradecemos aos pareceristas da revista Dados pelas sugestões que permitiram o aprimoramento deste artigo. Agradecemos também a todos os que participaram das discussões públicas e da mobilização política pela inserção do Bolsa-Cultura nos programas de governo dos candidatos a prefeito de São Paulo em 2012. Finalmente, agradecemos ao professor Ricardo Musse pelo apoio e à atual administração da Secretaria Municipal de Cultura de São Paulo pela disposição em implementar o programa.
}

DADOS - Revista de Ciências Sociais, Rio de Janeiro, vol. 56, no 2, 2013, pp. 351 a 382. 
ra diferentes e antagônicas, essas duas modalidades de financiamento têm em comum o tratamento mercantil dos bens e serviços culturais. A partir deste pano de fundo conceitual, discutimos duas experiências brasileiras recentes que, ao deslocar o foco do financiamento do produto para o processo, apontam para um tratamento não mercantil da cultura. Tomamos esses elementos como ponto de partida, os depuramos e os desenvolvemos num modelo do qual tiramos todas as consequências: pensar o financiamento cultural como o direito de produzir cultura.

\section{FINANCIAMENTO PÚBLICO VIA EDITAIS}

A política pública de cultura, no sentido moderno, nasce no pós-guerra com o objetivo declarado de proteger a cultura da força deletéria do mercado, criando subsídios diretos e indiretos e órgãos de seleção da distribuição dos recursos baseados no modelo científico de "revisão pelos pares", ou seja, da realização da seleção por especialistas. Esse tipo de política foi constituída com o objetivo de levar o "melhor para o maior número", na expressão consagrada de John Maynard Keynes, o que significa financiar a produção cultural considerada de excelência e criar mecanismos de acesso amplo a ela ${ }^{1}$. O financiamento público parte assim de uma lógica de subsídios, fornecendo recursos a atividades culturalmente relevantes que precisam ser democratizadas e que não encontram sua sustentabilidade no mercado ${ }^{2}$.

O processo do financiamento público nesta modalidade se dá com a abertura pelo estado de um edital disponibilizando um certo montante para financiar um determinado tipo de obra ou ação. Os editais lançados contêm necessariamente as normas para participação e condições de habilitação, os prazos para o desenvolvimento dos projetos e o tipo de ação a ser financiada ${ }^{3}$. O edital é divulgado e os interessados submetem projetos com a descrição da atividade proposta, seus objetivos e justificativa, o plano de execução com as etapas de realização (plano de trabalho ou cronograma de atividades), o orçamento detalhado e a qualificação do proponente e de todos os envolvidos (ficha técnica e currículo) ${ }^{4}$. Os projetos são então reunidos e avaliados no seu caráter formal (com relação à documentação exigida) e, em seguida, aqueles formalmente adequados são encaminhados para o julgamento de uma banca de especialistas. Esta banca avalia os projetos com base em critérios que podem ser mais ou menos definidos e que normalmente incluem: 1) a maior ou menor adequação do projeto ao objeto do edital, sua 
coerência e clareza interna, adequação do orçamento ao objetivo e viabilidade da execução; 2) o alcance do projeto no que diz respeito ao público estimado, estratégias de divulgação e tipo de público-alvo; 3) a qualificação dos profissionais envolvidos e/ou da instituição proponente; 4) a qualidade do projeto quanto à sua excelência ou mérito artístico ou cultural. Os projetos recebem então notas que podem ser atribuídas para o conjunto ou para cada um dos seus aspectos e, ao final da etapa de seleção, são hierarquizados numa classificação geral, permitindo que os recursos sejam distribuídos para os primeiros colocados. Os projetos contemplados definem-se assim a partir do montante de recursos disponíveis e da quantidade de projetos a serem financiados, variáveis também colocadas pelo edital. A partir dessa seleção, ocorre a contratação e o repasse da primeira parcela para a execução das ações, que segue necessariamente o cronograma e as etapas definidas no projeto. Ao final, o contratado deve comprovar que a atividade foi realizada estritamente como planejada por meio de um relatório narrativo das atividades desenvolvidas e um relatório financeiro com o detalhamento dos gastos realizados.

Essa modalidade de financiamento busca atingir dois tipos de resultados. Em primeiro lugar, busca subsidiar manifestações que são consideradas relevantes mas que não são sustentáveis - ou seja, o valor que obtêm com a venda de produtos e serviços não é suficiente para cobrir os custos de produção. Além disso, justamente pelo seu mérito cultural, considera-se que essas manifestações devem atingir um público amplo. Assim, o subsídio muitas vezes cobre não apenas a diferença entre os custos de produção e o que se consegue vender no mercado, mas financia a obra como um todo, exigindo como contrapartida que ela seja oferecida gratuitamente ou a um preço muito baixo. O resultado é uma política de financiamento público de obras culturalmente relevantes que são ofertadas gratuitamente ou a preços baixos sob a ótica da democratização do acesso. A proposta vincula-se assim a uma perspectiva difusionista, que visa a democratização da alta cultura ou da cultura considerada legítima, sendo esta definida a partir de critérios universais que as obras supostamente encarnam.

Este tipo de política recebeu duras críticas a partir dos anos 1970, principalmente de setores da esquerda. Em primeiro lugar, criticou-se o fato de que este tipo de política destina recursos públicos para manifestações culturais cujo consumo constitui formas de distinção (Bourdieu, 2007 [1979]). Afirma-se, nesse sentido, que os modos de apropriação 
dos bens culturais estão vinculados às condições sociais dos consumidores - em especial seu nível de instrução e origem social -, fazendo com que a fruição cultural dependa fortemente do domínio dos códigos específicos embutidos nas manifestações artísticas. O consumo cultural vincula-se assim ao acúmulo de capital cultural, por sua vez adquirido por meio de processos de socialização vinculados à posição social e ao habitus de classe. À hierarquia no universo das artes corresponde, portanto, uma hierarquia dos consumidores e, com isso, uma política orientada para subsidiar uma suposta excelência artística ou cultural aprofunda e referenda esse sistema de distinções ${ }^{5}$. Além de reforçar o corte de classe, esse tipo de ação do estado gera uma política regressiva de distribuição de recursos, já que subsidia com orçamento público produtos que são caracteristicamente consumidos pela elite que tem maior capital cultural acumulado ${ }^{6}$.

Esse tipo de política foi também considerada equivocada do ponto de vista econômico, ao insistir em criar público para produtos culturais que obviamente não têm demanda (Garnham, 1987 [1983]). Políticas deste tipo consideram que o público das obras subsidiadas, por ser incipiente, é incapaz de garantir o financiamento da produção cultural. No entanto, ao subsidiar as obras, a política desperdiça recursos públicos gerando a superprodução de bens que são estruturalmente subdemandados, fazendo dessa prática uma intervenção pública marginal no setor cultural.

Por fim, argumentou-se que esses recursos escassos voltados para subsidiar produtos elitistas com baixa demanda poderiam ser reorientados para o subsídio de outras manifestações culturais de apelo mais amplo. Emergiu daí a proposta não apenas de democratizar a difusão, mas também a própria produção cultural, contribuindo assim para a valorização da pluralidade dos sistemas culturais, que se orientaria para uma democracia cultural (Botelho, 2001).

Todas essas críticas serviram para se ver com distanciamento políticas que até os anos 1970 ou mesmo 1980 eram vistas como unânimes tanto nos meios liberais, como socialistas. No entanto, acreditamos que uma crítica adicional pode ser feita a esse modelo: a de que ele não supera a lógica de mercantilização do resultado do processo de produção cultural, limitando-se a comprar ou ajudar a comprar bens e serviços culturais. Isso significa que, ainda que os subsídios contribuam para a emancipação da lógica de mercado - no sentido da produção não de- 
pender da sua comercialização -, eles mantêm a forma de compra e venda, através do financiamento da produção e da difusão das obras pelo estado $)^{7}$.

A lógica deste tipo de financiamento se pauta, portanto, pelo financiamento da produção ou do acesso à obra e não do processo criativo que leva a ela. Quando este tipo de política se orienta para o financiamento do produto e não do processo, três consequências negativas surgem: a vulnerabilidade econômica dos proponentes de projetos; o engessamento do processo de produção cultural; e o reforço do julgamento de valor no que diz respeito à distribuição dos recursos.

No que diz respeito à vulnerabilidade econômica, os produtores de cultura que se dedicam a captar recursos públicos para projetos vivem no esforço constante de preparar projetos sólidos que, no entanto, podem ou não ser contemplados. Uma vez que os projetos financiados cobrem em geral apenas o processo de realização final da obra, todo o processo de pesquisa, desenvolvimento e concepção do projeto, que muitas vezes é a etapa mais longa e mais criativa do processo de produção, não é remunerado. Estas ricas e frequentemente demoradas etapas preliminares são realizadas com grande vulnerabilidade econômica e na mais absoluta incerteza quanto a se serão efetivamente realizadas. Além disso, dada a crescente especialização e profissionalização da etapa de redação e submissão de projetos, em muitos casos cria-se ainda a figura dos intermediários, o que gera dependência do produtor e aumento dos custos de elaboração dos projetos. Por fim, há vulnerabilidade adicional na incerteza do lançamento ou não de editais, já que eles frequentemente não têm uma periodicidade regular.

Uma outra consequência do modelo de financiamento de produtos e serviços é o engessamento do processo criativo. Isso ocorre porque no financiamento por projetos via editais públicos a execução das etapas que levam ao resultado que será financiado deve necessariamente seguir todos os passos inicialmente propostos, sob risco de penalização caso isto não ocorra. Os editais indicam que todas as alterações nos projetos devem ser não apenas informadas, como autorizadas, cabendo ao proponente do projeto inclusive a devolução do valor destinado à ação caso tenha havido mudanças não autorizadas pelo financiador. Se, por um lado, pode-se argumentar que isto garante o bom uso dos recursos públicos e o não desvirtuamento do objeto do contrato, por outro acaba por gerar uma série de entraves, uma vez que a dinâmica em que se in- 
serem os grupos culturais e artísticos é bastante mutável e há, inclusive, um espaço temporal relativamente longo entre o envio das propostas e a transferência do recurso que permite a execução do projeto. Assim, as mudanças no contexto de desenvolvimento do projeto não apenas autorizariam como indicariam a realização de alterações.

Finalmente, o financiamento de produtos e serviços depende necessariamente do modelo de avaliação pelos pares, que consiste no julgamento discricionário do valor estético ou cultural dos projetos sob análise. Quando as políticas concebiam a cultura apenas como belas artes, esse tipo de discernimento estético era ainda possível, já que as obras poderiam ser julgadas por critérios não objetivos, mas discerníveis, como os de contribuição para o desenvolvimento da linguagem (para as artes) ou de relevância histórica da obra preservada (para o patrimônio). No entanto, este conceito estrito de cultura tem sido questionado por outro tipo de política pública com um conceito mais amplo, próximo do antropológico, no qual as manifestações culturais ganham em diversidade, linguagens e funções sociais (Unesco, 1982) ${ }^{8}$. Essa nova abordagem foi precedida por amplos debates acadêmicos que argumentaram que a concepção predominante é restritiva e classista, na medida em que privilegia um processo específico de esforço criativo em detrimento da compreensão da cultura como experiência ordinária, vinculada à formação de significados e valores e, em última instância, aos modos de vida (Williams, 1989 [1958]; Bianchini, 1987).

Se já havia questionamentos sobre a arbitrariedade das escolhas estéticas no conceito restrito de cultura, no conceito ampliado elas são ainda maiores. No conceito restrito, a produção artística tinha uma pretensão de universalidade que autorizava a hierarquização, ainda que tal universalidade pudesse ser problematizada, como vimos. No conceito ampliado, no entanto, a compreensão da cultura enquanto formas de vida leva necessariamente à consideração de inúmeras manifestações particulares, impossibilitando a valoração hierárquica.

Com que critérios distribuir recursos entre as diferentes linguagens (dança, música, cinema, circo etc.) e mesmo entre práticas que não se enquadram neste tipo de classificação? Com que critérios, dentro de uma mesma linguagem ou prática, distribuir recursos entre os projetos concorrentes sem hierarquizá-los culturalmente, tendo em vista o grau de subjetividade implicado nesse tipo de perspectiva? Não à toa os editais para financiamento público da cultura concentram-se bastante em 
elementos menos subjetivos como a organização interna do projeto e o tamanho estimado do público receptor ${ }^{9}$ e deixam deliberadamente vago - e, portanto, fortemente sujeito ao julgamento arbitrário - o critério de julgamento do valor cultural do projeto, descrito como "mérito da proposta" (no edital do programa VAI da prefeitura de São Paulo), "qualidade técnica do projeto" (no edital ProAC do Estado de São Paulo) ou "qualidade do projeto" (nos editais da Funarte).

Assim, ainda que estes tenham escopos diferenciados no que diz respeito ao público-alvo, às territorialidades a que se destinam, aos prazos de execução dos projetos, aos valores e formatos de repasse, às despesas permitidas e à divisão ou não por linguagens artísticas, os editais seguem sujeitos a um julgamento que dá poder discricionário para juízes competentes hierarquizarem culturalmente as propostas.

Todos esses problemas decorrem da lógica do financiamento pontual, que se destina à etapa final da produção ou difusão de bens e serviços culturais. É a partir destas considerações que apresentaremos adiante uma nova proposta de financiamento estatal, orientado a processos e não apenas à compra de produtos.

\section{FINANCIAMENTO MERCANTIL}

O segundo paradigma de financiamento da cultura que buscamos analisar é o financiamento puramente mercantil. Neste, há a vinculação da produção cultural e artística à lógica do mercado, que se pauta pela compra e venda de produtos e está submetida às variações do preço e da demanda. A produção de mercadorias e serviços mercantis culturais não é nova ${ }^{10}$, mas é relativamente nova a orientação das políticas públicas de promover e fomentar a produção da cultura por meio do mercado. Ela é resultado, por um lado, das críticas que foram feitas às políticas tradicionais de levar "o melhor ao maior número" e, por outro, das críticas gerais das correntes neoliberais à intervenção do estado na economia.

Além disso, a partir das discussões sobre a sociedade da informação e do conhecimento, que colocam no centro do desenvolvimento econômico os produtos e atividades informacionais, no início dos anos 2000, o próprio setor cultural começou a se mobilizar para ganhar prestígio junto à administração pública, por meio de políticas de fomento às "indústrias criativas" (DCMS, 2001; UNCTAD, 2004; European Commission, 2006). Essas políticas para as indústrias criativas, basicamente, bus- 
cavam associar o setor tradicionalmente entendido como cultural a outros setores "criativos", como o software e a publicidade, de maneira a criar um conjunto economicamente relevante que fosse digno de uma maior atenção por parte do estado. Assim, desde os relatórios do Departamento de Mídia, Cultura e Esporte do Reino Unido, começou-se a estimar a participação no emprego e no Produto Interno Bruto (PIB) do setor criativo, entendido como o setor que congrega as atividades econômicas nas quais a criatividade é um elemento relevante de geração de valor. Desta maneira, o setor cultural começou a reivindicar maior espaço no conjunto das políticas públicas, mas o resultado tem consistido geralmente numa subordinação da política cultural à lógica da política industrial, com a aplicação aos setores criativos de mecanismos de fomento industrial como políticas de crédito e de isenção fiscal.

Com essas políticas reapareceram as deficiências históricas do financiamento mercantil à cultura: a imposição de padrões e esquemas a uma atividade essencialmente criadora; a subordinação da lógica simbólica da produção cultural à lógica de rentabilidade dos investimentos; a necessidade de que a venda dos produtos e serviços culturais gere valor suficiente para cobrir os custos de produção; e as barreiras de preço para o acesso aos bens e serviços culturais.

O primeiro dos problemas foi evidenciado pela crítica da Escola de Frankfurt que denunciava os padrões e esquemas impostos pela indústria à atividade cultural, desprovendo-a de valor estético. Como os investidores são avessos ao risco, eles a plicam capital apenas em obras que reproduzem padrões extraídos de outras obras que já foram bemsucedidas economicamente. O acúmulo e depuração desses esquemas gera um conjunto de regras rígidas a que todo produtor cultural comercial tem que se submeter se quiser financiamento e o resultado é a profusão de obras homogêneas e padronizadas que são desprovidas da dinâmica criadora e inovadora que é característica do campo cultural (Adorno, 1986 [1941]; Adorno e Horkheimer, 1986 [1947]).

O segundo problema, relacionado ao primeiro, é que, numa obra pensada predominantemente como produto, o interesse econômico subordina a lógica simbólica. Como o produtor depende da venda do bem cultural para a sua subsistência, sempre que a lógica do campo cultural entrar em choque com a lógica do campo econômico, a segunda prevalecerá. Assim, há uma subordinação da atividade criadora aos padrões e gostos já estabelecidos do público consumidor, este também ligado 
ao contexto da indústria cultural. Assim, quanto mais próximos da lógica comercial, mais os produtos tendem a se adequar à demanda existente, por sua vez ligada a formas preestabelecidas de produção (Bourdieu, $\left.1996[1992]^{11}\right)$.

Além desses problemas, há também a impossibilidade de se produzirem bens culturais cujo valor arrecadado com a venda não seja suficiente para cobrir os custos de produção. Atividades muito custosas, seja porque são de grande escopo ou porque incorporam um grande número de produtores devem ter um preço elevado ou encontrar um número de consumidores tão grande quanto seus custos. Em outras palavras, bens culturais onerosos ou são inviáveis economicamente ou precisam ser ainda mais intensamente subordinados à lógica econômica do comercialismo e dos conteúdos esquemáticos.

Por fim, o paradigma mercantil dificulta o acesso à cultura, uma vez que o consumo cultural passa a depender fortemente de recursos econômicos, vinculando o acesso à capacidade de pagamento. Como a venda do produto deve pelo menos cobrir os custos de produção da obra, ela tem um patamar mínimo de preço que frequentemente está acima da capacidade de consumo dos cidadãos. Desta forma, o acesso à cultura - que é um direito constitucionalmente garantido ${ }^{12}$ - transforma-se de fato em um privilégio daqueles que têm recursos econômicos, com a maior parte da população tendo um padrão de consumo notavelmente baixo ${ }^{13}$ (Silva, 2007).

\section{EM BUSCA DE UM NOVO MODELO}

Partimos dessas considerações que caracterizam e apontam os limites do financiamento estatal e mercantil para teorizar um novo modelo de financiamento por parte do estado, que proporcione uma justa remuneração dos produtores e dos seus processos criativos e formativos. Os dois modelos apresentados anteriormente, ainda que se diferenciem em inúmeros aspectos, aproximam-se na medida em que se inserem dentro de uma lógica de compra e venda de produtos e serviços. No primeiro caso, isso se dá por meio do financiamento público que simplesmente subsidia a compra de produtos e serviços que são considerados culturalmente relevantes e que não têm mercado suficiente para cobrir os custos de produção. No segundo caso, isso se dá diretamente no mercado, ainda que possa ser auxiliado pelo estado, na medida em que bus- 
ca apoiar o fluxo nas cadeias produtivas por meio de políticas tributárias e de crédito.

A proposta que apresentamos aqui se diferencia de ambas e consiste no financiamento das atividades culturais e não de seus produtos. Essa proposta resolve de maneira que julgamos adequada uma série de problemas do financiamento mercantil e do financiamento público da cultura. Em relação ao financiamento público, ela permite reduzir a vulnerabilidade econômica dos produtores ao financiar todo o processo e não apenas o momento final de execução ou difusão; reduz ainda, com isso, o engessamento do processo, dando maior liberdade ao produtor e à própria proposição dos projetos. Além disso, permite superar as arbitrariedades do processo de seleção que, na prática, contradizem o conceito ampliado de cultura adotado pela política pública contemporânea.

Em relação ao financiamento mercantil, ela permite ampliar o consumo ao subsidiar a produção da obra e garantir sua fruição independentemente da capacidade de pagamento; permite superar os problemas de subordinação da lógica simbólica à lógica econômica, gerando mais pluralidade e proporcionando maior liberdade de criação; por fim, permite também superar as dificuldades de financiamento de projetos de grande escopo, seja porque reúnem muitos produtores seja porque têm longa duração no tempo.

A atividade cultural é uma atividade que se desenvolve em um tempo estendido, sendo o produto gerado ou serviço fornecido por esta apenas o resultado final. Estes produtos e serviços são construídos a partir de esforços constantes de criação e pesquisa, assim como de formação dos produtores, o que faz do processo anterior à geração do produto o momento mais rico e importante da produção cultural. Por isso, é necessário valorizar e financiar esse longo momento anterior "oculto" que se constitui como atividade encarnada de sentido, gerando impactos culturais, econômicos e sociais muito além de seus produtos.

Discutiremos no final deste artigo os mecanismos para efetivar tal proposta, mas lembramos que esta é uma prática cuja lógica fundamental já está em curso, uma vez que há nas políticas culturais brasileiras pelo menos duas iniciativas que se aproximam dela: a Lei de Fomento ao Teatro da cidade de São Paulo e o programa federal Cultura Viva, analisados a seguir. Partimos assim da observação de experiências existentes para teorizar de forma mais aprofundada um modelo que privilegia o 
direito ao fazer cultural sobre a lógica mercantil da compra e venda de produtos e serviços.

\section{FINANCIAMENTO DA CULTURA COMO PROCESSO}

O Cultura Viva é um programa federal de financiamento de associações e grupos culturais já estabelecidos, que recebem apoio para continuar suas atividades por um período de três anos, segundo um plano de trabalho proposto. O programa foi estabelecido em 2004 e inovou ao beneficiar agentes culturais e comunitários periféricos ${ }^{14}$ que não eram tradicionalmente atendidos pelas políticas culturais.

Embora a perspectiva que informa o programa estivesse presente desde o início da gestão Gilberto Gil, a proposta a princípio consistia na construção das Bases de Apoio à Cultura (chamadas BACs), que se concretizariam por meio da construção de centros culturais pré-moldados nas comunidades produtoras de cultura. Ainda que voltados às comunidades, as BACs priorizavam a estrutura e o espaço físico sobre as práticas culturais.

O Cultura Viva, que substitui a proposta das BACs, tem como foco a produção e a difusão de atividades culturais de grupos e associações que já desenvolviam trabalhos na área da cultura (entendida numa acepção antropológica). Assim, ao invés de financiar grandes obras culturais (no sentido tradicional das belas artes) ou grandes equipamentos públicos, os recursos do Ministério da Cultura eram pulverizados em pequenos valores (180 mil reais para três anos) distribuídos entre centenas e depois milhares de grupos comunitários.

Essas mudanças compunham um conjunto significativo de inovações na maneira de se fazer política cultural: a adoção do conceito antropológico de cultura; o financiamento "aberto" destinado a práticas culturais sem objetos predefinidos; o financiamento de práticas culturais já existentes; e a maior valorização do processo, em oposição aos produtos culturais.

Em primeiro lugar, a abordagem ligada ao conceito antropológico de cultura buscou incluir práticas diversas e novas expressões e atores no campo das políticas culturais, ampliando o escopo do financiamento estatal à cultura. A esta mudança de abordagem correspondeu o direcionamento de recursos para além das tradicionais linguagens artísticas. Com isso, o financiamento não só deixa de direcionar recursos a um 
campo específico, como admite uma série de práticas ligadas à cultura popular, aos modos de fazer tradicionais, quando não à interação entre as mais diversas formas de expressão cultural, que vão da tradição oral à cultura digital. Isso não quer dizer, no entanto, que o programa deixa de financiar projetos ligados às linguagens artísticas - ele na verdade amplia o campo das políticas culturais para outras manifestações ${ }^{15}$.

Além de ampliar o conceito de cultura, no programa são os grupos e instituições que propõem os projetos e atividades que desejam realizar, fazendo com que o estado acolha a diversidade das iniciativas culturais desenvolvidas pela sociedade civil. Isso acontece porque no edital do programa não há objetos predefinidos para financiamento. Assim, ainda que os pontos de cultura sejam contemplados com os recursos a partir de uma seleção feita via edital e da proposição de um plano de trabalho, a proposta do programa se diferencia do modelo de financiamento estatal na medida em que proporciona uma maior liberdade aos projetos, já que a estruturação dos planos de trabalho pode-e deve - ser feita a partir da especificidade de cada instituição proponente e de suas necessidades e dinâmicas próprias. Nesse sentido, o recurso não é destinado à elaboração de determinado produto ou manifestação cultural, mas seu uso é definido pelos próprios proponentes, vinculando-se de maneira mais próxima à perspectiva da ação cultural (Coelho, 2001) e da garantia do direito à cultura.

A proposta consiste ainda no financiamento de práticas culturais já existentes, buscando fazer uma espécie de do-in antropológico, seguindo o famoso discurso de posse de Gilberto Gil (2003), ministro da Cultura à época da criação do programa. Assim como o do-in é uma massagem que se concentra em um ponto localizado para ter efeitos sobre todo o corpo, também o Cultura Viva deveria apoiar pontos de cultura dispersos pelo território nacional buscando com isso atingir um impacto social mais amplo. A política consistia, portanto, em destinar recursos estatais anteriormente concentrados em grandes projetos para pequenas atividades em curso, potencializando uma produção social dispersa que já existia.

Por fim, mas não menos importante, deve-se destacar que o financiamento volta-se com isso aos processos culturais, valorizando as atividades e agentes envolvidos e não os possíveis produtos a serem desenvolvidos. Segundo Célio Turino, idealizador do programa, os pontos de cultura não são equipamentos culturais ou serviços, mas compreen- 
dem a cultura como processo, levado a cabo de forma autônoma e a partir do protagonismo de seus agentes (Turino, 2009:64). O Cultura Viva pauta-se, portanto, por uma lógica de valorização dos processos e fluxos embutidos nas práticas culturais. Destaca-se assim um modelo de financiamento não de eventos ou produtos específicos, mas de processos - o que inclui a possibilidade de manutenção de determinados fazeres culturais existentes e a valorização dos agentes culturais a partir de suas próprias demandas - com a garantia de um financiamento de mais longo prazo.

Com o passar dos anos, o programa ganhou força, tendo sido criados mais de três mil pontos de cultura em todo o Brasil. Parte deste sucesso deve-se à adoção de uma estratégia de crescimento baseada na descentralização, tirando o programa da alçada exclusiva do Ministério da Cultura e transferindo, a partir de 2007, parte do financiamento e da gestão administrativa dos pontos de cultura a estados e municípios.

No que diz respeito à operacionalização, os pontos de cultura são selecionados a partir do lançamento de editais, voltados tanto à seleção dos pontos propriamente ditos, quanto ao desenvolvimento de ações específicas dentro do programa ${ }^{16}$. Assim, as instituições proponentes submetem seus projetos conjuntamente com a documentação exigida e, sendo atendidos os pré-requisitos, as propostas são avaliadas por uma comissão julgadora com base em critérios voltados à avaliação técnica do projeto (viabilidade técnica; capacidade de realização do proponente; alcance cultural e social; abrangência do público-alvo; adequação do orçamento e viabilidade do plano de trabalho) e análise de mérito, que por vezes se coloca como um dos critérios da análise do projeto (São Paulo, 2009) e em alguns casos como uma terceira etapa do processo (Distrito Federal, 2009). Para aqueles projetos aprovados, estabelece-se um convênio entre o órgão governamental responsável e as instituições proponentes, que passam a executar suas ações a partir dos planos de trabalho, devendo prestar contas ao final de cada etapa do projeto, isto é, no fim de cada ano.

Apesar do sucesso do programa, alguns problemas foram se revelando ao longo do processo de implementação. Em primeiro lugar, mantiveram-se as dificuldades com a proposição de projetos, muitas vezes permanecendo a figura do atravessador/captador, dado o grau de exigência e detalhamento necessários. Além disso, permaneceu também a análise do mérito, característica dos modelos de financiamento estatal 
voltados às belas artes, o que se evidencia em critérios de seleção como a "qualidade cultural do projeto proposto", apenas para citar o edital de seleção da rede estadual paulista (São Paulo, 2009).

Além destas questões relacionadas à seleção dos projetos, temos ainda as dificuldades envolvendo sua execução. $\mathrm{O}$ estabelecimento de convênios com as instituições proponentes, assim como o regimento dos procedimentos pela lei 8.666/93, trouxeram consigo uma série de difíceis regras burocráticas no que diz respeito ao uso dos recursos, entre elas a necessidade de realização de três orçamentos e licitação para compra de bens ou contratação de serviços, a necessidade de aplicação dos recursos do convênio, a impossibilidade de pagamento dos dirigentes da instituição e da realização de gastos administrativos superiores a $15 \%$ do valor total do projeto.

O excesso de regras e exigências colocadas quanto aos procedimentos burocráticos, somado à ausência de estrutura administrativa e contábil de muitos pontos de cultura e à falta de capacitação prévia dos agentes, acabou por gerar uma série de entraves com relação às prestações de contas. O foco na questão contábil e na realização desta série de procedimentos acabou por corroer grande parte das energias dos agentes envolvidos, quando não geraram consequências mais graves, inclusive com a necessidade de devolução de recursos ${ }^{17}$. Essas inflexíveis regras burocráticas também bloquearam o livre desenvolvimento dos projetos, já que qualquer pequena alteração nos planos de trabalho precisava ser informada e aprovada pelo órgão responsável, o que tornava inviável a adaptação do planejamento prévio a novas circunstâncias.

Boa parte destes problemas relativos à prestação de contas foram, pelo menos num primeiro momento, tratados de maneira adequada pela Lei Municipal de Fomento ao Teatro da cidade de São Paulo. Nesse sentido, chamam a atenção o procedimento de prestação de contas desburocratizado e o financiamento do processo de criação teatral, inclusive sem a exigência de contrapartida em termos de produtos (no caso, a produção de espetáculos teatrais).

Instituído pela Lei 13.279/02 (Lei de Fomento ao Teatro), o programa entra em vigor em 2002, após um período de forte mobilização e reivindicação por parte de artistas e grupos de teatro na cidade (Kinas, 2010; Costa e Carvalho, 2008). Como surge para atender as demandas práticas dos grupos teatrais em atividade, ela incorpora como valor central 
uma rejeição da visão mercantil da arte, assim como da visão do teatro como evento (Movimento Arte contra a Barbárie, 1999).

Ainda que voltada a uma linguagem específica dentro do universo das práticas culturais, esta iniciativa caminha na mesma direção do Cultura Viva, na medida em que visa contribuir com processos permanentes de criação. A própria lei determina como seu objetivo primordial "apoiar a manutenção e criação de projetos de trabalho continuado de pesquisa e produção teatral" (São Paulo, 2002: art. 1), compreendendo assim a cultura como um processo de longa duração e não como um somatório de eventos e produtos ${ }^{18}$.

Assim, os grupos podem receber financiamento pelo período de até dois anos, não havendo exigência de contrapartida em termos de produção. O programa financia não peças de teatro - como costuma ocorrer nas experiências de financiamento estatal - mas o processo criativo dos grupos, realizando um investimento de longo prazo e que permite o desenvolvimento das atividades de pesquisa e investigação teatral dos grupos de maneira autônoma. Aqui, vale destacar, constitui inclusive critério de julgamento das propostas a realização de planos de ação continuada que não se restrinjam a um evento ou uma obra (art. 14, II), o que demonstra o compromisso da política com a perspectiva do financiamento às atividades constantes e ao processo artístico e criativo como um todo.

Da mesma forma que no programa Cultura Viva, os recursos são destinados a grupos selecionados a partir de propostas enviadas e da análise de uma comissão julgadora, com notório saber na área. Ainda assim, por se tratar de uma lei, a política é contínua e há seleção de projetos com periodicidade definida ${ }^{19}$, não estando sujeita às oscilações dos editais.

Vale destacar ainda que, até 2010, para a submissão dos projetos não havia um formato padrão definido previamente, estando estabelecida pela própria lei a impossibilidade de que a Secretaria Municipal de Cultura o fizesse (art. 8). Com isso, procurava-se manter, mais uma vez, a autonomia dos proponentes e garantir maior flexibilidade para as propostas. No que diz respeito à prestação de contas, esta lógica também se mantinha, uma vez que a comprovação era feita por meio do envio de relatórios de atividade ao órgão responsável, bastando a comprovação da execução do objeto, sem necessidade do modelo contábil de comprovação dos gastos realizados. Desta maneira conciliava-se a necessidade 
de proteger os recursos públicos do uso inadequado com o imperativo de não onerar o produtor cultural com procedimentos burocráticos rígidos que atrapalhassem a realização das atividades-fim.

Essa desburocratização era tão central ao programa que, quando foi modificada pelo Decreto 51.300 de 22 de fevereiro de 2010 (São Paulo, 2010), foi considerada pelas companhias teatrais como sua descaracterização completa. $\mathrm{O}$ decreto - resultado de longos embates entre a administração e os grupos de teatro -, modificou a lei, impondo padrões de elaboração de projetos e prestação de contas na forma tradicional dos convênios (art. $9^{\circ}$ ).

Essa breve análise das características principais dos dois programas mostra que, a despeito das diferenças em termos de linguagens e territorialidade, eles inovam ao criar novas formas de financiamento não vinculadas aos produtos e serviços culturais. As duas iniciativas evidenciam assim uma lógica de financiamento à cultura enquanto processo. Além disso, evidenciam pelos seus acertos e pelos desafios de implementação que é necessário também inovar nas formas de prestação de contas, de maneira a simplificar os procedimentos burocráticos, gerando mais flexibilidade (fundamental ao desenvolvimento das práticas culturais), menor comprometimento de tempo à gestão dos projetos e diminuindo ou eliminando o papel dos intermediários ${ }^{20}$.

Partiremos dessas considerações quanto às potencialidades e desafios destas duas experiências para a proposição de um modelo de financiamento à cultura, detalhado adiante.

\section{A PRODUÇÃO DA CULTURA COMO DIREITO}

A proposta que apresentamos aqui parte da identificação dos elementos inovadores destas duas políticas (Cultura Viva e Lei de Fomento ao Teatro) e busca depurá-los e tomá-los de base para a constituição de um modelo inovador de política cultural. Este modelo se caracteriza pelo financiamento do processo de produção e não do produto cultural e pela desburocratização da prestação de contas, de maneira a preservar a flexibilidade do desenvolvimento dos projetos e a respeitar a informalidade dos agentes. Acreditamos que essas duas características já presentes nas políticas (e também nas tentativas de aprimorar essas políticas) apontam para um novo paradigma que pode e deve ser integrado com as discussões sobre uma renda básica de cidadania. 
A renda básica de cidadania consiste "no pagamento de uma renda por parte da comunidade política para todos os seus membros, de maneira individual, sem critérios de seleção ou exigência de trabalho" (Van Parijs, 2004), isto é, no pagamento universal, para todos os cidadãos, de uma renda, sem nenhum tipo de contrapartida. A ideia tem sido discutida há muito tempo e recentemente ganhou destaque no debate político como uma modalidade eficiente e socialmente justa de direito social. Trata-se, por um lado, de uma modalidade de ação social que reduz ou elimina a vulnerabilidade econômica de todos os cidadãos; por outro lado, reconhece o caráter coletivo e difuso do processo de geração de riquezas, funcionando como uma espécie de recompensa social pelo simples pertencimento à comunidade.

A convergência destas modalidades de financiamento cultural e da renda básica de cidadania não é uma proposta, mas uma constatação - na verdade, uma explicitação das consequências do desenvolvimento da lógica interna dessas políticas culturais. Elas apontam para um modelo depurado, no qual o financiamento da produção cultural não estaria mais submetido a uma lógica de compra de produtos, mas se configuraria como um direito social que seria progressivamente universalizado.

No Brasil já está em curso a implementação gradual de uma renda básica de cidadania por meio da expansão do Bolsa Família, um programa de transferência de renda ainda condicional (as famílias devem levar as crianças à escola e ao posto de saúde) e orientado para famílias de baixíssima renda (Suplicy, 2006). Nos parece muito adequado que a porta de entrada para a renda cidadã sejam as populações economicamente vulneráveis num país onde ainda existe fome e pobreza extrema. Mas a expansão de uma política focada (para famílias de baixa renda) para uma política universalista tem enfrentado grandes obstáculos (Brito e Soares, 2010). Esses obstáculos consistem na resistência de parcela expressiva da opinião pública em conceder um benefício social que poderia estimular a ociosidade e o "parasitismo social" (que os anglo-saxões chamam de free riding $)^{21}$.

Devido a esta resistência da opinião pública, parece claro do ponto de vista político que este direito social universal terá que ser construído a partir da multiplicação das portas de entrada, com políticas focadas que apresentem certas condicionalidades que respondam às críticas de "parasitismo". Além disso, como é um direito muito oneroso para o estado, acredita-se que a renda básica precise ser construída incorporan- 
do direitos sociais já existentes, ao invés de sobrepor-se a eles (Van Parijs, 2004). Por isso, parece-nos duplamente oportuno que se adotem políticas culturais que apontem para a renda básica de cidadania, abrindo uma segunda e concomitante porta de entrada para este direi$\mathrm{to}^{22}$. Por um lado, essa proposta reforça a lógica inerente às novas modalidades de financiamento da cultura; por outro, ela constitui uma espécie de recompensa coletiva pelo caráter social da produção da cultura. Nos parágrafos anteriores discutimos a conveniência desta proposta do ponto de vista da lógica da política cultural brasileira. Gostaríamos agora de discutir a sua conveniência da perspectiva da recompensa social.

Desde os anos 1970, a Economia e a Sociologia discutem a emergência de uma economia da informação ou do conhecimento, na qual o centro dinâmico de geração de valor se deslocou da produção industrial para processos de manipulação de informações. Segundo essas teorias, estaríamos assistindo à emergência de uma modalidade de capitalismo na qual os ganhos de produtividade se devem fundamentalmente à introdução de novas tecnologias (Abramovitz, 1993) e na qual a estrutura ocupacional é crescentemente composta de atividades comunicativas e de tratamento de informações - e não de processamento e manipulação de produtos físicos (Castells, 2007).

Se é verdade que estamos caminhando para uma sociedade na qual a geração de riqueza depende da aplicação do conhecimento às atividades econômicas e na qual o trabalho consiste cada vez mais na comunicação e no processamento de informações, então a ciência e a cultura, no seu sentido social difuso, estão no centro do processo econômico.

Como uma ampla literatura começa a demonstrar, o conhecimento e a cultura que estão na base da produção de riquezas são sociais em pelo menos três aspectos. Em primeiro lugar, a ciência (e também o conhecimento produtor de tecnologia) não surge no vácuo, mas é codeterminada por um processo social de aprendizagem e interação que inclui aulas, papers, congressos e seminários, mas também a observação da prática social. Sem essa interação simbólica que dá à atividade científica uma dimensão internacional, intergeracional e interinstitucional, para usar a fórmula de um sociólogo clássico (Merton, 1973 [1942]), não seria possível a ciência. Essa interação é tão difusa que normalmente não é possível determinar com precisão como e em que medida 
cada pessoa ou cada autor do passado contribuiu para a produção da "descoberta" presente.

Em segundo lugar, como defendem com muita eloquência Alperovitz e Daly (2010 [2008]:63), esse conhecimento é crescentemente dependente da herança passada. À medida que o progresso tecnológico avança, a contribuição científica e tecnológica acumulada das gerações anteriores passa a ser cada vez mais determinante para a produção presente da riqueza. Em outras palavras, a cada geração a produção de riqueza depende menos da nossa contribuição pessoal e mais da contribuição do passado, na forma de capital, savoir faire organizacional e tecnologia acumulados.

Essas características sociais do processo de produção de riquezas sugerem que há grande justiça em recompensar um processo social difuso com uma contrapartida difusa como a remuneração individual universal. A renda básica seria assim a recompensa para a sociedade como um todo pela sua contribuição difusa, passada e presente, no processo de conhecimento que gera valor. Em outras palavras, todos nós teríamos direito a uma parte da riqueza social porque nós e nossos antepassados contribuímos direta e indiretamente para produzi-la.

Mas, além disso, há uma especificidade da natureza das ocupações no capitalismo informacional que justifica que a introdução deste direito universal tenha como uma de suas portas de entrada os produtores culturais.

Desde os anos 1990, Manuel Castells tem mostrado (1994 e 2007), por meio de evidências empíricas, que a natureza do trabalho no capitalismo contemporâneo mudou. Num estudo sobre a estrutura ocupacional do G7, Castells notou que, nesses países, de um terço até metade da força de trabalho se dedica hoje a atividades comunicacionais ou de manipulação de informações - em outras palavras, a atividades que consistem em comunicação e trabalho de computador e não em tratamento ou manipulação de objetos naturais ou produtos industriais.

A expansão deste tipo de trabalho - que não é apenas do cientista e do músico, mas também do advogado, do secretário, do operador de telemarketing e do contador-é dependente de um processo social difuso: a cultura. Essas atividades econômicas requerem dos trabalhadores não só criatividade, como capacidade de expressão e manipulação de símbolos, de maneira que a competência para executá-las está ancorada na interação cultural. Dito de outra maneira, a aquisição de repertórios 
simbólicos e a competência para expressá-los e manipulá-los é inseparável do processo de criação e fruição cultural - o que em política cultural chamamos de natureza cíclica da produção da cultura (Unesco, 2009:19-21), na qual o consumo e a participação são condições sine qua non para a criação.

Essa característica do processo cultural faz dos produtores culturais os catalizadores do enriquecimento cultural requerido pelas novas atividades profissionais. Isso não quer dizer que os produtores culturais sejam o motor do capitalismo informacional, mas apenas que são elementos fundamentais, na medida em que ampliam e reorganizam o repertório que será demandado pelas atividades produtivas de comunicação e manipulação de símbolos. O papel estratégico que ocupam neste novo sistema produtivo faz deles (assim como dos professores e cientistas) candidatos naturais a primeiros beneficiários desta renda de cidadania, que deverá depois se estender a toda a sociedade. Por esse motivo, sugerimos que as políticas culturais adotem explicitamente o modelo do direito social universal como princípio organizativo e norteador do financiamento da cultura - até porque, por razões intrínsecas ao desenvolvimento das políticas, elas já caminham para isso.

\section{Um Modelo de Política para a Cultura como Direito}

Neste artigo, argumentamos que tanto as políticas de financiamento público da cultura como as que se dão por meio do mercado adotam uma lógica de compra e venda de produtos e serviços culturais. $\mathrm{Na}$ contramão dessa lógica, políticas culturais brasileiras recentes como o Cultura Viva e a Lei Municipal de Fomento ao Teatro têm adotado uma lógica de financiamento de processos. Apontamos também a convergência entre esse tipo de política cultural e as políticas de implementação da renda básica de cidadania. Esse conjunto de considerações nos leva a propor um modelo de financiamento da cultura que incorpore e radicalize os princípios imanentes às experiências do Cultura Viva e da Lei de Fomento ao Teatro: um financiamento que não se volte para o produto, mas para o processo; que seja estrutural e aponte para a universalidade; que desburocratize e flexibilize a aplicação de recursos; e que colabore para a democratização do acesso à cultura. Para facilitar o entendimento de que maneira o modelo que estamos propondo desenvolve ideias contidas no Cultura Viva e na Lei de Fomento ao Teatro e, ao mesmo tempo, se diferencia dos paradigmas do financiamento público via edital e do financiamento puramente mercantil, apresenta- 


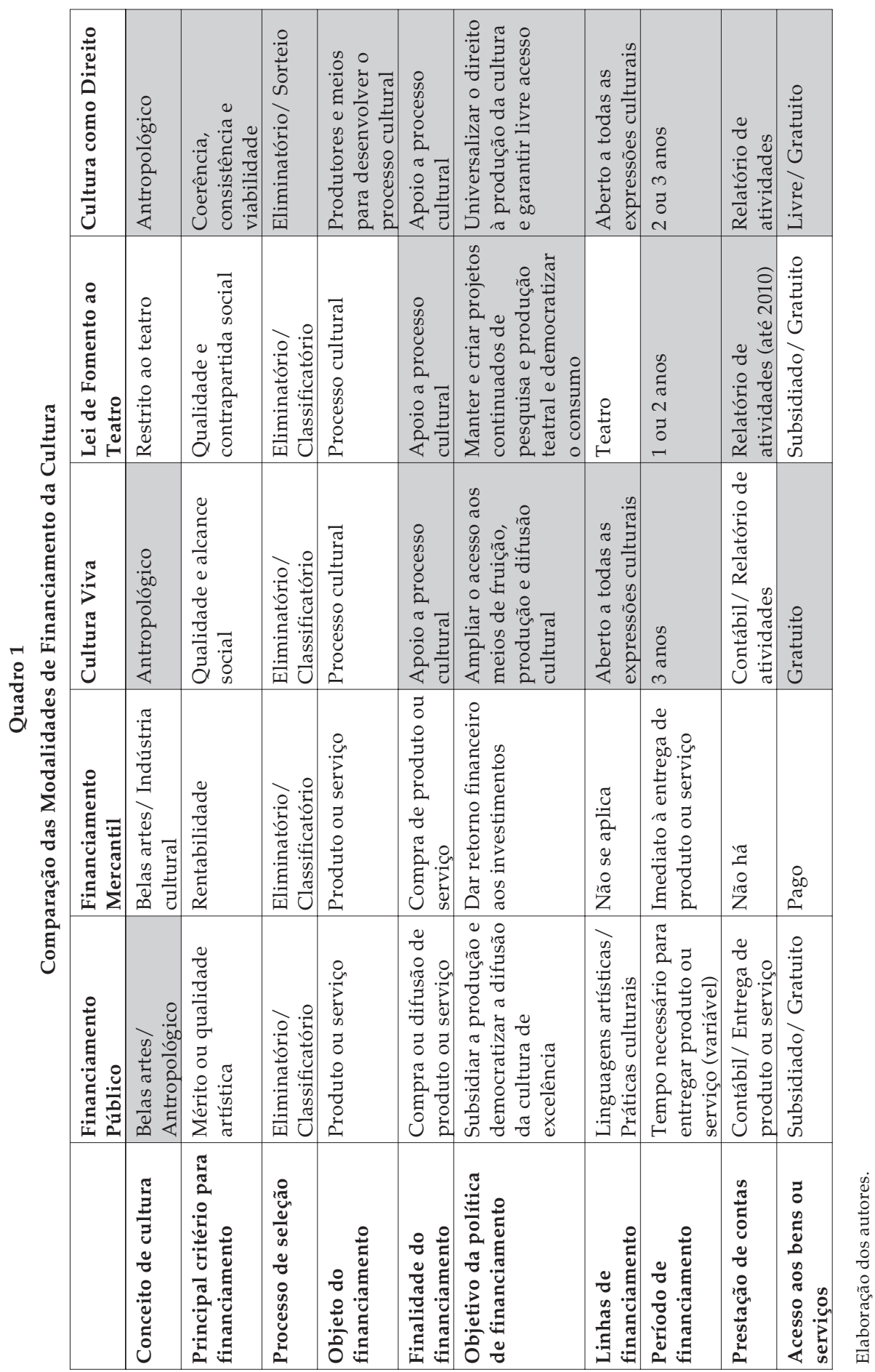

DADOS - Revista de Ciências Sociais, Rio de Janeiro, vol. 56, nำ 2, 2013 
mos um quadro explicativo e comparativo. Finalmente, discutimos detalhadamente algumas características do modelo proposto:

Financiamento do processo e não do produto - Essa é a característica mais visível das iniciativas como o Cultura Viva e a Lei de Fomento ao Teatro. Elas buscam financiar todo o processo criativo que inclui a pesquisa, a formação e o ensaio e não apenas o produto final. Assim, os processos criativos que precedem a elaboração do projeto que descreve o produto passam a ser financiados, reduzindo a vulnerabilidade econômica dos produtores. Além desse aspecto, a proposição dos projetos torna-se com isso simplificada, na medida em que, ao financiar as etapas anteriores à produção, não há necessidade de se prever o resultado final. Por fim, não há o engessamento do processo, uma vez que prevê-se a capacidade de planejamento mas não há a necessidade de seguir à risca todas as etapas propostas ou receber autorização para realizar alterações ${ }^{23}$.

Prazos de vigência longos - Prazos de vigência longos, de dois ou três anos, são condições necessárias para o financiamento do processo criativo completo e não apenas do produto ou serviço final. Além disso, prazos assim contribuem também para a redução da vulnerabilidade econômica dos agentes, permitindo um planejamento de mais longo prazo e evitando gasto de energia para a captação constante de recursos e submissão de projetos a editais.

Remuneração per capita com adicionais por projeto - Para aperfeiçoar as iniciativas em curso, acreditamos que o financiamento deve ser proporcional ao número de produtores principais diretamente envolvidos, de maneira a mais explicitamente caminhar para uma lógica da renda básica ${ }^{24}$. Custos adicionais de projeto que não são a remuneração mensal do trabalho dos produtores principais diretamente envolvidos podem ser financiados de maneira complementar, segundo estimativa de gasto enviada junto à proposição do projeto.

Processo seletivo eliminatório e não classificatório - Um dos principais problemas hoje na seleção de projetos é que eles ainda incorporam critérios de "qualidade cultural" que não encontram mais apoio nos princípios contemporâneos da política pública de cultura, como vimos. Talvez por esse motivo, o critério de qualidade, que frequentemente se transforma num julgamento arbitrário e puramente subjetivo, é dissolvido numa série de outros critérios que dispõem de parâmetros definidos. Para evitar os problemas de hierarquização cultural, sugerimos 
que os processos de seleção sejam eliminatórios e não classificatórios, ou seja, que se selecionem os projetos que se adequam à proposta e que não seja feita uma classificação com base em pontuações para que sejam contemplados os primeiros colocados. Os projetos devem ser analisados nos seus elementos constitutivos e avaliados apenas se são coerentes, consistentes e viáveis, isto é, se há clara definição dos objetivos (culturais) que se busca alcançar, se há compatibilidade do projeto com o prazo de vigência, compatibilidade do número de produtores proposto com a natureza da atividade e compatibilidade do orçamento dos custos adicionais do projeto (além da remuneração dos produtores principais) com os valores de referência (Indicador de Preços da Cultura). Além disso, a seleção deve avaliar se os proponentes e produtores envolvidos estão qualificados pela sua trajetória pregressa para realizar a atividade proposta ${ }^{25}$. Desta maneira, avalia-se o projeto "internamente", sem a necessidade de hierarquizar culturalmente as linguagens e as diferentes expressões - como implicitamente ainda se faz hoje.

$\mathrm{Na}$ ausência de recursos suficientes para contemplar todos os selecionados, sorteio - Como em muitos casos a demanda de financiamento de projetos excederá a oferta de recursos, deve-se optar pelo sorteio entre os projetos que passaram pela seleção eliminatória. A adoção do princípio do sorteio é muito alheia ao funcionamento das nossas instituições democrático-liberais que tradicionalmente adotam mecanismos meritocráticos de seleção. No entanto, a equitatividade do sorteio é a contrapartida necessária da adoção de um conceito antropológico de cultura, já que este impede que as escolhas sejam influenciadas por critérios de juízo estético. Além disso, o sorteio é fortemente autorizado pela tradição - basta lembrar que para Aristóteles o sorteio é o método de seleção democrático por excelência, enquanto a eleição do melhor é um método caracteristicamente aristocrático (Aristóteles, 1988:1294b). O sorteio é mais caracteristicamente democrático porque nele todos os concorrentes estão em iguais condições, ou seja, ele pressupõe a equidade como ponto de partida. Já nas modalidades de seleção meritocráticas (eleição ou classificação), o ponto de partida é o de que há uma diferença de qualidade entre os concorrentes e de que apenas os melhores devem ser atendidos. Enquanto no sorteio o pressuposto é a igualdade do direito, na eleição e classificação o pressuposto é a desigualdade. No caso em questão, o sorteio parece adequado por dois motivos que se reforçam: porque com advento do conceito antropológico de cultura não é mais aceitável pressupor que há expressões culturais melhores ou superiores a outras; e porque numa política orientada para o direito universal 
não é correto privilegiar com os poucos recursos disponíveis justamente aqueles "melhor capacitados", cuja "superioridade" é resultado de processos anteriores marcados por condições desiguais.

Prestação de contas desburocratizada e flexível - O debate avaliando a implementação do programa Cultura Viva trouxe duas posições antagônicas: por um lado, aqueles que dizem que o processo de prestação de contas da Lei 8.666/93 (lei de licitações) nega os princípios democratizantes do programa ao impedir que grupos pouco estruturados administrativamente consigam estar adimplentes; e, por outro, aqueles que dizem que embora a prestação de contas seja efetivamente burocrática, ela garante o bom uso dos recursos públicos e que a lei de licitações é uma importante conquista democrática. Acreditamos que esse debate pode ser superado se olharmos o financiamento da cultura sob dois novos prismas: para a parcela do financiamento cultural destinado a remunerar os produtores deve prevalecer a lógica do direito social e, para a parcela do financiamento destinado a remunerar os outros gastos do projeto, deve prevalecer a lógica do prêmio. Já discutimos nos parágrafos anteriores a adequação da lógica do direito. No próximo item discutiremos a lógica do prêmio.

Comprovação da realização das atividades, não do gasto - Se houver uma séria avaliação eliminatória do projeto, cada projeto aprovado terá demonstrado consistência interna entre o objetivo e os meios necessários para realizá-lo e o orçamento detalhando os custos desses meios terá sido julgado com respeito a sua razoabilidade face a valores de referência (Indicador de Preços da Cultura). O financiamento dos gastos que não são a remuneração per capita dos produtores deve se dar então na modalidade de "prêmio". Nesta modalidade, projetos meritórios (não numa relação comparativa e culturalmente hierarquizada, mas meritórios pela sua coerência, consistência e viabilidade e pela competência pregressa dos envolvidos) seriam premiados com um valor capaz de cobrir os custos de realização do projeto. Como se trata de um prêmio, a visão de que é necessário um monitoramento minucioso do gasto conveniado perde sentido. Para se evitar que projetos sejam propostos e não realizados e o prêmio consumido de outra maneira, basta que se avalie o relatório final de atividades e que autores de relatórios insatisfatórios percam a capacidade de concorrer com novos projetos ou, no caso de não realização das atividades, tenham de devolver os recursos. Se o projeto propunha uma sequência de meios para realizar um objetivo, se esses meios foram avaliados como razoáveis e se depois se 
comprovou a realização do objetivo, não há a necessidade de monitorar cada gasto específico submetendo-o aos burocráticos procedimentos de comprovação. Essa flexibilidade se justifica por dois motivos importantes: 1) grupos culturais não estruturados administrativamente podem concorrer sem o risco de alta inadimplência que, por exemplo, o programa Cultura Viva gerou; 2) a execução de projetos de processo e não de produto são muito mais susceptíveis a condições, circunstâncias e elementos não previstos e, portanto, a incorporação de flexibilidade na execução dos gastos é uma necessidade deste tipo de financiamento.

Contrapartidas de acesso - Finalmente, é preciso que uma política que democratize o subsídio à produção cultural tenha como contrapartida a democratização do acesso, completando o ciclo da produção da cultura a que já nos referimos. Assim, dos beneficiários do financiamento deve-se exigir contrapartidas de acesso que basicamente são preços baixos ou gratuitos para atividades de performance e licenças livres de direito autoral para bens culturais de produção seriada (como CDs, DVDs e livros). Desta maneira, os recursos públicos que subsidiaram a produção cultural permitem que ela seja fruída com baixa ou nenhuma barreira de preço, além de permitir que essas criações possam ser incorporadas por outras obras criativas ${ }^{26}$.

(Recebido para publicação em junho de 2012)

(Reapresentado em setembro de 2012)

(Aprovado para publicação em março de 2013) 


\section{NOTAS}

1. Sobre a trajetória de Keynes e seu papel fundamental nas modernas políticas culturais inglesas, veja Upchurch (2011).

2. Em nossa análise optamos por não tratar diretamente das problemáticas envolvendo as formas de financiamento via renúncia fiscal, representadas no Brasil pelo paradigma da Lei Rouanet. Isso porque nesses casos há claramente um modelo híbrido, que envolve o uso de recursos públicos a partir de decisões privadas no que diz respeito à alocação. Essa modalidade se caracteriza assim por uma mescla dos dois modelos de financiamento em análise, o estatal e o mercantil, envolvendo inclusive o financiamento de atividades propriamente de mercado, que não necessitariam de financiamento público para garantir a sua sustentabilidade. Também não tratamos do financiamento público por meio da ação direta do estado (na forma de teatros e museus públicos, por exemplo), já que na tradição brasileira essa modalidade de financiamento é basicamente restrita aos grandes equipamentos.

3. Nesse último ponto, no entanto, há variações, havendo desde aqueles que definem apenas o público-alvo prioritário, como no caso do Programa para a Valorização de Iniciativas Culturais (VAI) da cidade de São Paulo, até a definição de ações específicas, como nos vários editais lançados pela Funarte e pelo Programa de Ação Cultural do Estado de São Paulo (ProAC).

4. Há ainda casos em que se exigem outras informações complementares, como a existência de contrapartida por parte do proponente, a autorização de uso do espaço onde se realizará o projeto ou mesmo materiais que embasam a produção como roteiros, textos, gravações demonstrativas etc. O fundamental, no entanto, vincula-se ao escopo do projeto em termos de localização e público e ao tipo de ação desenvolvida (circulação, exibição e distribuição, exposição, montagem de acervo, realização de oficina ou curso, pesquisa e documentação, produção de espetáculo, evento, produção de vídeo ou CD e assim por diante).

5. Embora sua obra tenha sido lido desta maneira (como uma crítica antielitista à distinção), é preciso ressaltar que a política cultural defendida por Bourdieu (pelo menos em seus últimos escritos) consistia "em trabalhar para universalizar as condições de acesso à universalidade", reconhecendo, portanto, a universalidade da obra de arte no sentido convencional kantiano (Bourdieu, 1990:388). Para a evolução da posição de Bourdieu a esse respeito veja Gartman (2011).

6. Nesse sentido, não bastam portanto as políticas de subsídio que garantem o acesso ao consumo em termos econômicos, ou seja, pelo oferecimento de produtos e serviços gratuitos ou a baixo custo.

7. Apenas a título de exemplo, em 2011 os editais lançados pelo ProAC destinaram-se ao financiamento de primeira gravação de disco, primeira obra de artes visuais, primeira obra de artes cênicas, publicação de livros, texto inédito de dramaturgia, circulação de espetáculos musicais, produção de espetáculo de dança, difusão e circulação de espetáculo de dança, produção de número circense, criação e / ou manutenção de site de cultura e assim por diante.

8. Em 1982 uma conferência da Unesco estabeleceu a seguinte concepção ampliada de cultura: "no sentido amplo, pode-se considerar a cultura como o complexo total de características espirituais, materiais, intelectuais e emocionais que distinguem uma 
sociedade ou grupo social. Ela inclui não apenas as artes e as letras, mas também os modos de vida, os direitos fundamentais do ser humano, os sistemas de valores, tradições e crenças" (Unesco, 1982).

9. Nesse ponto, notamos que a valorização do público, em especial em seu aspecto quantitativo, aproxima o financiamento público via editais dos mecanismos de funcionamento do mercado, recompensando aquelas obras que encontram grande público consumidor. Embora, por um lado, isso permita escapar das críticas contra o financiamento de produtos sem mercado consumidor, por outro lado, permite o surgimento de efeitos deletérios como a serialização, característica do modelo mercantil (veja discussão a seguir).

10. É preciso observar que, historicamente, o financiamento mercantil cumpriu um papel progressista ao emancipar o financiamento da produção cultural das ingerências do mecenato. O financiamento mercantil deslocou a fonte dos recursos que subsidiavam a produção cultural dos grandes mecenas para o grande público, gerando democratização do financiamento e maior liberdade de expressão. Ainda assim, esse processo trouxe consigo novos problemas, discutidos a seguir. A esse respeito veja Bourdieu (1974).

11. “Um empreendimento está tanto mais próximo do polo 'comercial' quanto os produtos que oferece no mercado correspondem mais direta ou mais completamente a uma demanda preexistente e em formas preestabelecidas. [...] Tem-se assim [...] empreendimentos com ciclo de produção curto, visando minimizar os riscos por um ajustamento antecipado à demanda detectável e dotados de circuitos de comercialização e de procedimentos de valorização (publicidade, relações públicas etc.) destinados a assegurar o recebimento acelerado dos lucros por uma circulação rápida de produtos reservados a uma obsolescência rápida" (Bourdieu, 1996 [1992]:163).

12. O direito à cultura parte do entendimento de que a cultura constitui elemento imprescindível para o exercício da cidadania, sendo hoje considerado direito fundamental no ordenamento jurídico brasileiro. Neste, o direito de acesso à cultura é considerado um dos quatro pilares estruturantes dos direitos culturais: o direito à participação, $\mathrm{o}$ direito de acesso, o direito à pluralidade e à diversidade e o direito à memória (Souza, 2012:cap.4).

13. De acordo com pesquisa realizada pelo Instituto de Pesquisa Econômica Aplicada (Ipea) (Silva, 2007), os brasileiros $40 \%$ mais pobres respondem por $10 \%$ do dispêndio cultural geral, enquanto os $10 \%$ mais ricos respondem por $40 \%$ dos gastos em cultura. Aqui desconsideram-se as práticas culturais não vinculadas a pagamento, evidenciando especificamente o caráter desigual do mecanismo mercantil.

14. É considerado público-alvo prioritário do programa, conforme a Portaria no 156 , de 6 de julho de 2004, que o constituiu: populações de baixa renda; estudantes da rede básica de ensino; comunidades indígenas, rurais e quilombolas; agentes culturais, artistas, professores e militantes que desenvolvem ações no combate à exclusão social e cultural (Portaria n을 156, art. $3^{\circ}$ ).

15. São exemplos de atividades ligadas ao universo dos pontos de cultura tanto oficinas e apresentações de grupos de teatro, música e dança quanto a realização de festas e eventos populares, iniciativas ligadas ao desenvolvimento local, à economia solidária, à difusão de determinados saberes e fazeres e práticas como a da capoeira, do artesanato de tradição, da culinária e assim por diante. 
16. Os pontos de cultura, vale dizer, são a base sobre a qual se desenvolvem e se articulam as outras ações do programa, tais como a Cultura Digital, a Escola Viva, a Ação Griô e o Agente Cultura Viva, além dos prêmios para realização de eventos e articulação da rede de pontos de cultura.

17. A questão tomou dimensão tal que chegou a ser reivindicada a anistia dos pontos de cultura, sobretudo nos casos em que os erros foram decorrentes do fornecimento de informações incorretas por parte do poder público (Comissão Paulista de Pontos de Cultura, 2011). Além disso, no caso da rede estadual paulista, criada em 2009, tentou-se estabelecer a parceria com o governo estadual na forma de prêmio (São Paulo, 2009: art. 2.1), o que a princípio não exige a conciliação bancária e a apresentação de notas fiscais, mas apenas uma planilha demonstrativa do uso dos recursos, além dos relatórios de atividades e comprovação do cumprimento do objeto. Ainda que haja incerteza quanto ao modelo adotado em São Paulo, entendemos que o formato tornaria a prestação de contas um processo mais simplificado, valorizando o impacto gerado e as atividades realizadas em detrimento dos procedimentos financeiros, podendo ser assim uma alternativa para lidar com o problema.

18. Já no processo de mobilização, vale dizer, afirmava-se ser fundamental a existência de um processo continuado de trabalho e pesquisa artística e a criação de mecanismos estáveis e permanentes de fomento à pesquisa e experimentação teatral (Movimento Arte contra a Barbárie, 1999).

19. A seleção é feita duas vezes ao ano, em períodos predefinidos, sendo as inscrições realizadas sempre em janeiro e junho. Além disso, é destinado anualmente ao programa uma rubrica no orçamento do município.

20. Nesse aspecto, a política do programa de Valorização de Iniciativas Culturais da prefeitura de São Paulo (VAI) pode ser considerada também um modelo de prestação de contas simplificada.

21. Curiosamente, no entanto, a renda cidadã tem sido apresentada na literatura acadêmica justamente como uma política que evita o parasitismo - pois, ao contrário de políticas de seguro-desemprego, por exemplo, cria um patamar mínimo universal que se soma ao salário da atividade laboral ao invés de competir com ele.

22. Essa estratégia de construção paulatina, por meio de múltiplas portas de entrada e a partir de políticas focadas que devem ser crescentemente expandidas exige planejamento por parte do formulador já que no futuro essas políticas confluiriam numa só, inclusive no que diz respeito ao montante dos rendimentos. É um problema para o futuro, mas sobre o qual precisamos estar cientes, dadas as assimetrias de remuneração dos beneficiados pelo bolsa família e daqueles que recebem recursos pelas políticas culturais. Na literatura sobre a renda básica, a saída proposta é que a renda básica se transforme num piso de remuneração ao qual se somem outros rendimentos complementares de políticas específicas condicionais.

23. Nesse ponto, podemos tomar como modelo as políticas de financiamento à pesquisa científica, em que a proposição dos projetos pressupõe um cronograma mínimo de atividades, porém há flexibilidade para alterá-lo de acordo com o andamento da pesquisa e as necessidades que aparecem no decorrer do próprio projeto.

24. Neste ponto também podemos evocar o exemplo do financiamento à ciência, no qual o montante do financiamento é proporcional ao número de pesquisadores envolvidos que receberão bolsas. 
25. Um dos inconvenientes de se exigir capacitação prévia dos envolvidos é que novos atores não teriam apoio para começar sua produção. Isso poderia ser contornado reservando um percentual dos recursos - digamos, $20 \%$ - para esses novos atores como fazem, por exemplo, certas sociedades de gestão coletiva da música na Europa que repassam um percentual de $20 \%$ dos royalties da execução musical para fomentar a música nova e independente.

26. Essa proposta foi apresentada aos candidatos a prefeito de São Paulo nas eleições municipais de 2012. Três candidatos se comprometeram a implementá-la caso eleitos, inclusive o candidato vencedor. Em 2013, a proposta do Programa Bolsa-Cultura, inspirada neste artigo, foi incorporada no plano de governo do município, com previsão de implementação em 2014. 


\section{REFERÊNCIAS BIBLIOGRÁFICAS}

ABRAMOVITZ, Moses. (1993), “The Search for the Sources of Growth: Areas of Ignorance, Old and New". The Journal of Economic History, vol. 53, no 2, pp. 217-243.

ADORNO, Theodor W. (1986) [1941], "Sobre a Música Popular", in G. Cohn (org.), Theodor W. Adorno: Sociologia. São Paulo, Ática. pp. 115-146.

ADORNO, Theodor; HORKHEIMER, Max. (1986 [1947]), A Dialética do Esclarecimento. Rio de Janeiro, Zahar.

ALPEROVITZ, Gar; DALY, Lew. (2010) [2008], Apropriação Indébita: Como os Ricos Estão Tomando a Nossa Herança Comum. São Paulo, Senac.

ARISTÓTELES. (1988), Política. Lisboa, Vega.

BIANCHINI, Franco. (1987), “GLC R.I.P.: Cultural Policies in London - 1981-1986”. New Formations, no 1, pp. 103-117.

BOTELHO, Isaura. (2001), "Dimensões da Cultura e Políticas Públicas". São Paulo em Perspectiva, vol. 15, no 2, pp. 73-83.

BOURDIEU, Pierre. (1990), “The Scholastic Point of View". Cultural Anthropology, vol. 5, no 4, pp. 380-391.

(1996) [1992], As Regras da Arte: Gênese e Estrutura do Campo Literário. São Paulo, Companhia das Letras.

(2007) [1979], A Distinção: Crítica Social do Julgamento. São Paulo, EDUSP.

BRASIL. (1993), Lei n-8.666, de 21 de junho de 1993. Institui normas para licitações e contratos da Administração Pública e dá outras providências.

(2004), Portaria no 156, de 06 de Julho de 2004. Dispõe sobre a criação do Programa Cultura Viva. Brasília, 06 de jul. de 2004.

BRITTO, Tatiana; SOARES, Fábio Veras. (2010), Bolsa Família e Renda Básica de Cidadania: Um Passo em Falso? Brasília, Centro de Estudos da Consultoria do Senado.

CASTELLS, Manuel. (2007), A Sociedade em Rede: A Era da Informação. São Paulo, Paz e Terra.

; AOYAMA, Yuko. (1994), “Paths Towards the Informational Society: Employment Structure in G7 Countries, 1920-1990". International Labour Review, vol. 133, no 1, pp. 5-33.

COELHO, Teixeira. (2001), O que é Ação Cultural. São Paulo, Editora Brasiliense.

COMISSÃO PAULISTA DE PONTOS DE CULTURA. (2011), Carta da Comissão Paulista de Pontos de Cultura para Ministra Ana de Hollanda. Brasília, 22 de fevereiro.

COSTA, Iná Camargo; CARVALHO, Dorberto. (2008), A Luta dos Grupos Teatrais de São Paulo por Políticas Públicas para Cultura: Os Cinco Primeiros Anos da Lei de Fomento ao Teatro. São Paulo, Cooperativa Paulista de Teatro.

DCMS. (2001), Creative Industries Mapping Document. London, Department of Culture, Media and Sport.

DISTRITO FEDERAL. Secretaria de Estado de Cultura. (2009), Edital de Seleção para Pontos de Cultura do Distrito Federal. Brasília, 29 de setembro.

EUROPEAN COMMISSION. (2006), The Economy of Culture in Europe. European Commission. 
GARNHAM, Nicholas. (1987 [1983]), “Concepts of Culture: Public Policy and the Culture Industries". Cultural Studies, vol. 1, no 1, pp. 23-37.

GARTMAN, David. (2011), "Bourdieu and Adorno: Converging Theories of Culture and Inequality". Theory and Society, vol. 41, no 1, pp. 41-72.

GIL, Gilberto. (2003), Discursos do Ministro da Cultura Gilberto Gil. Brasília, Ministério da Cultura.

KINAS, Fernando. (2010), “A Lei e o Programa de Fomento ao Teatro para a Cidade de São Paulo. Uma Experiência de Política Pública Bem-Sucedida”. Revista Extraprensa, vol. 1, no 1 .

MERTON, Robert. (1973) [1942], “The Normative Structure of Science”, in N. W. Storer (ed.), The Sociology of Science: Theoretical and Empirical Investigations. Chicago, University of Chicago Press.

MOVIMENTO ARTE CONTRA A BARBÁRIE. (1999), Manifesto Arte contra a Barbárie. São Paulo.

SÃO PAULO (Município). (2002), Lei no 13.279, de 8 de janeiro de 2002. Institui o "Programa Municipal de Fomento ao Teatro para a Cidade de São Paulo" e dá outras providências.

SÃO PAULO (Município). (2010), Decreto no 51.300 de 22 de fevereiro de 2010. Regulamenta a celebração de convênios e instrumentos congêneres e as respectivas prestações de contas, no âmbito da Secretaria Municipal de Cultura.

SÃO PAULO (Estado). Secretaria de Estado da Cultura. (2009), Edital de Seleção para Pontos de Cultura do Estado de São Paulo. São Paulo, 24 de junho.

SILVA, Frederico Barbosa et alii. (2007), "O Consumo Cultural das Famílias Brasileiras", in F. G. Silveira et alii (orgs.), Gasto e Consumo das Famílias Brasileiras Contemporâneas. Brasília, IPEA.

SOUZA, Allan Rocha. (2012), Os Direitos Culturais no Brasil. Rio de Janeiro, Azougue Editorial.

SUPLICY, Eduardo Matarazzo. (2006), Renda Básica de Cidadania: A Resposta Dada pelo Vento. Porto Alegre, LP\&M.

TURINO, Célio. (2009), Ponto de Cultura: O Brasil de Baixo para Cima. São Paulo, Anita Garibaldi.

UNCTAD. (2004), Creative Industries and Development. Geneva, UNCTAD.

UNESCO. (1982), Mexico City Declaration on Cultural Policies. World Conference on Cultural Policies. Cidade do México, 26 de julho-6 de agosto.

(2009), The 2009 UNESCO Framework for Cultural Statistics. Montreal, UNESCO Institute for Statistics.

UPCHURCH, Anna Rosser. (2011), “Keynes's Legacy: An Intellectual's Influence Reflected in Arts Policy". International Journal of Cultural Policy, vol. 17, no 1, pp. 69-80.

VAN PARIJS, Philippe. (2004), "Basic Income: A Simple and Powerful Idea for the Twenty-first Century". Politics \& Society, vol. 32, no 7, pp. 7-39.

WILLIAMS, Raymond. (1989) [1958], “Culture Is Ordinary”, in R. Gable (ed.), Resources of Hope. London, Verso, pp. 3-18.

DADOS - Revista de Ciências Sociais, Rio de Janeiro, vol. 56, nº 2, 2013 


\begin{abstract}
From the Purchase of Cultural Goods and Services to the Right to Produce Culture: Analysis of an Emerging Paradigm

Cultural activities are normally financed according to two classic paradigms: government funding and market financing. The former consists of direct state action or funding of civil society's cultural practices with state resources; the latter is anchored in the liberal or neoliberal tradition, the most recent expression of which involves the dominant currents of the creative economy. Based on a theoretical review and the analysis of two Brazilian policies - the Cultura Viva or "Living Culture" program and the Law for the Promotion of Theater in the city of São Paulo - we argue that these experiences constitute the genesis of a third paradigm that we identify and develop. This paradigm does not seek to finance cultural products per se, but the cultural production process, and thus aims to establish a social right, namely the right to produce culture.
\end{abstract}

Key words: cultural policies; cultural financing; basic income

\title{
RÉSUMÉ
}

De l'Achat de Produits et Services Culturels au Droit de Produire de la Culture: Analyse d'un Paradigme Émergent

Le financement des activités culturelles renferme deux paradigmes classiques: le financement public et le financement issu du marché. Le premier consiste soit dans l'action directe de l'État soit dans le financement, avec l'aide de l'Etat, d'activités culturelles de la société civile; le second repose sur la tradition libérale ou néolibérale dont l'expression la plus récente réunit les courants dominants de l'économie criative. À partir d'une révision théorique et de l'analyse de deux politiques publiques brésiliennes - le programme Cultura Viva et la Loi d'Aide au théâtre de la ville de São Paulo - on soutient dans cet article que ces expériences représentent la genèse d'un troisième paradigme à la fois isolé et développé ici. Celui-ci ne cherche pas à financer des produits culturels, mais le processus de production culturelle et s'oriente ainsi vers la constitution d'un droit social: le droit de produire la culture.

Mots-clés: politiques culturelles; financement culturel; revenu de base 